\title{
Modeling is designed to promote cultural tourism with approach future studies (Case Study: Esfahan)
}

\author{
Ali Lavafan ${ }^{1}$,Yasaman Sanayei $i^{2}$ \\ ${ }^{1}$ Researcher in Research Institute of ShakhesPajouh ,Isfahan ,Iran \\ Yasaman Sanayei ${ }^{2}$ \\ ${ }^{2}$ Assistant Professor Research Institute of ShakhesPajouh ,Isfahan ,Iran \\ Yasaman_sanayei@yahoo.com
}

\begin{abstract}
:
Cultural tourism is a move from people to visit cultural attractions with the aim to obtain new information and experience in order to satisfy the cultural needs. Esfahan can be considered as one of the world's major cities and a unique exception due to the body of the city which can be regarded as a valuable solid unit carrying specific Thinking and viewpoints.

Esfahan is not only a crystallization of a worldview but because of its spatial variation, it is one of the most unique cities with dozens of historical, cultural, religious, and natural attractions. The restructuring the global economy is the main factor of which depends the future of sustainable development, major changes being needed in the human behavior, In order to raise people's sensitivity regarding the importance of constructing ties between natures and cultures, between different world culturesmust be used as efficiently as possible. This case studymay be considered a useful instrument for identifying malfunction in the touristic sector in the south of Esfahan region, in order to supply all necessary information for further development strategies and policies in the field. The statistics in tourism is used in the study of the most stable features of touristic activity behaviour. This study will allow the configuration of a general outlook, which is necessary in order to take the best decisions when it comes to elaborating forecasts in the field.
\end{abstract}

Key words:Cultural Tourism, Future Studies, Esfahan, sustainable development.

\section{Council for Innovative Research}

\section{Peer Review Research Publishing System}

Journal: Journal of Social Sciences Research

Vol. 8, No. 2

jssreditor.cir@gmail.com

www.jssronline.com 


\section{INTRODUCTION:}

Iran has a long-term plan to develop of its tourism industry, especially cultural tourism in view of the depth and richness of its cultural and historic sites and

Cities[1].As far as I seen in this field, these impacts have not fully studied in Iran and, inparticular, in the city of Esfahan which was and is historically a major destination for both domestic and foreign tourists[2,3]. Therefore, this study aims to take into

consideration the social impacts as well as the economic benefits of tourism in Esfahan[4] .Many writers looking at the relationship between cultural heritage and tourism have viewed it as one inevitably involving conflict, including conflicts of

Interest between visitors and the host community[5]. This is not necessarily the case and tourism in stable, mature destinations that have historically received both domestic and foreign visitors - as Esfahan has since the 18th century where tourism is regarded as playing an important role in the social, cultural and economic fabric of the local community[6] .The primary goal here is to establish a theoretical and empiricalstudy for the city of Esfahan, enabling future comparative analyses of host attitudes[7] . A sample was chosen from among local residents and regression analysis was applied in order to discover if there are any underlying dimensions concerning their attitudes towards tourism development, and whether socio-economic and demographic characteristics can be useful predictors of these attitudes [8]. Tourism is one of the important issues in global economic and an important source of foreign exchange earning for developed and developing countries. Nowadays, tourism industry has attracted considerable amount of planning efforts and investments.

Tourism development depends on several factors such as transportation, living

standards, tourism industrialization, and identification and satisfaction of tourist's

needs, and wants[9].A phenomenon such as tourism plays an important role

in creating this situation and strengthening the common characteristics among people.

\section{Destination choice model}

Tourists are not homogenous in the way they experience destinations. Previous

experiences, different expectations and different values lead to different perceptions of services. For example, while one traveler might perceive late or bad service as a

shocking experience, another can perceive the shortcomings as an expected event.

While certain tourists allow for more risk, and expect less, their inherent motivations

and expectations also differ[10].

Tourists' behaviors in choosing a particular destination involve several dimensions

. Sociocultural, economic and safety dimensions are commonly

related to selecting a specific destination. In addition, choice of destination depends on specific biographical characteristics such as age, income or geographical distance[11]. Others refer to determinants such as situational inhibitors, climate, prices, quality, partner, fear and health. Moreover, researchers distinguish between both pull and push motives as determining factors for destination choice. In any case, a touristdevelops a risk perception, expects value for money and reflects upon certain choicecriteria. These criteria can be based on earlier experiences, stories told by others oreven brochures and materials from websites provided by representatives at thedestination [12].

\section{Study Methods and Empirical Results}

A quantitative methodological approach chosen forthis research and so aquestionnaire was handed to arandom sample of Esfahan's residents. It is widely

recognized in the literature that the main advantage ofa quantitative approach is that it can measure thereactions of a great number of people to a limited setof questions, which facilitates comparison andstatistical aggregation of the data [13]. Postal surveys havebeen said to be more appropriate because of theirrelatively quick and low-cost way for collectinginformation for a city of the size of Esfahan. However, because of lack of availability of thenecessary information about residents, an insufficientinfrastructure as well as cultural attitudes towards thatkind of method of data collection, this was not deemedappropriate in this case. A further positive aspect tothis direct sampling method is the presence of aninterviewer to prevent any misinterpretation of thequestions in the questionnaire. The survey instrument used in this studycomprised a subset of items originally developed foruse in rural American communities in Colorado thathave subsequently undergone slight adjustmentsbefore being applied to historic cities. The surveyinstrument consisted of two sections that were retainedin the historic cities instrument. The first included 28questions and required respondents to rate their levelof agreement with each on a five-point scale, fromstrongly disagree (1) to strongly agree (5). Each ofthese items related to general aspects of tourismdevelopment, sharing an interest in a particular issueand thus enabling the creation of sub-scales. Anadditional questionnaire item related to whether or notresidents were positive about tourism when they spoketo each other about its presence in the city. The secondsection looked for socioeconomic and demographicinformation in order to: verify, as far as possible, thesimilarity of the surveys; to identify the number oftimes 
residents were entering the city (for shopping,recreation and work); and to calculate the averagelength of their visits. In addition, respondents wereasked to report whether or not they had a familyhistory of residence in the area [11].

\section{Definitions and Concepts}

Tourism is a collection of phenomena and relationships arising from the interaction of tourists, investors,governments and the host communities, universities and NGOs in the process of absorption, transport, reception andcontrol of drawing tourists and other visitors[9].However, the tourism can be seen as an industry (Or a set of related industries), it also consists of a set of complex social phenomena [12]. Tourism is one the largest, broadest and fastest growing industries in the world which is an important source of revenue, employment and investment in many countries. However, its rapid

development has harmful effects on the environment in many parts of the world. Tourism is one of the common tools to stimulate crisis economies and promoting the development level through businesses and assetsthat can be nurtured. Tourism experiences are different. Part of it is derived from the various tourism forms and part due to the different strengths of the destination to attract tourists and provide their needs. Cultural tourism is defined in two dimensions[13] . In the conceptual terms, cultural tourism is defined as people's move toward cultural attractions and their separation from the usual place of residence with the intent of gaining new knowledge and experience to satisfy the cultural needs. In technical terms, cultural tourism is defined as human movement toward specific cultural attractions such as heritage sites, aesthetic and cultural symbols, arts and theater which are outside the usual place of residence [14].

\section{Results}

In general, there were no differences between textual and pictorial representation

in cultural components in tourism. The frequency of use of both textual and pictorial

representations of culture varied significantly between the study sites. The results suggestthat high culture, especially historical heritage, is significant in Iran tourism, popularculture is vital in Esfahan tourism, and festivals and special events are key elements incultural tourism.Local culture is vitally important in tourism and is emphasized and portrayed byvivid images of people, activities and buildings through words and pictures in brochuresin tourism marketing. However, it is hard to make a conclusion that the primary focus ofthe tours is on experiencing culture.

Brochures are not a main promotional tool in China in practice due to their limited availability. Brochures were regarded as being an expensive means of promotion. The distribution of brochures was not comprehensive. However, operators of government, travel agencies and tourism attractions more and more realize the importance of promotional brochures; other tools such as guide books, videos, tour guides and so forthcould compensate for the shortage of printed information that is distributed.

\section{Discussion}

The aim of this study was to examine the attitudes oflocal residents towards economically-inspired tourismdevelopment in the historic city of Esfahan. As stated above, this is the first study to consider specifically thesocial impacts of tourism development in Iran in anhistoric city with such a large population size. This

study has been shown to support our prediction thatthose residents who gain economic benefits are moresupportive of this industry than others and they

support further development. It has been found that, asthe level of employment fell, residents were morelikely to increase their support for the development of

this industry and related businesses. Those with lowerincomes will more easily accept to see their citybecoming a more major destination for the flow of

tourism and this finding is in the line with socialexchange theory. It has also been seen that, if wages inthe tourism industry begin to fall relative to wages in

the rest of the city's economic activities, then we willsee even those currently benefiting from this industrywill develop a resentment towards tourism. Further

studies of Esfahan or, more widely, of other historiccities in Iran and elsewhere must ask whethersocioeconomic and demographic characteristics canact as useful predictors of the likely attitudes of localresidents to any tourism development.

\section{Reference:}

[1] Ameli, S, (2009), the study of TehranVirtualCity, analytical approach to public spaces, Volume 1, TehranMunicipality.

[2]Gharakhloo, Mehdi, Shabanifard, Mohammad (2007). Job satisfaction of employees of Hajj and Pilgrimage

.Organization of Tehran city and its relation to cultural tourism, geographical landscape, 2 (5), 73-94 
[3] Ghiasrad, I., 2008. "The relationship between manager's view and manager's affairs and other tourism in Iran" Olympic journal, 16(3): 115-119.

[4] Hafiz Nia, M (2008): Introduction to Research in the Humanities Science, the Samt publisher.

[5] Honarvar, H., 2005. The factors of tourism development caused by sports events in Iran.From the view of management and marketing principles. Tehran universities.

[6] Madhush, M., and N. Naser pour, 2003.Tourism industry development obstacles in Lorestan province, journal of Commerce, 28: 25-58.

[7] Moharamzade, M., 2005."Study of the method of marketing in universities' providing educational opportunities.Physical educational office.Oromiehuniversity.HajtapeUniversity and Turkey University.

[8] Moienfar, 2008., "the situation of pre-post games tourism management in Iran and providing the development's pattern. Doctrine thesis, TehranUniversity

[9] Mokhtari, Malekabadi,R (2010), Information and communication Technology, origin for modeling and sustainable development Ecotourism, The first Symposiums of Information and communication Technology and ecotourism industry development, engineering power and computer, shahrekord.

[10] Ravdrad, A Haji Mohammadi A (2010), recognizing the difference between real and virtual tourism based on narrative theory, Journal of Cultural Studies, Volume III, No.2

[11] Roche, S., 2013.A model of sporting event tourism as economic development. Sport, Business and Management: An International Journal.3(2): 147-157

Sajadi, F., 2006."The scientific study of the roles of tourism in Esfahan tabatabaie universities.

[12] SeyedahmadBeheshti,,ImanZare, (2012),promotional strategies for attraction of foreign tourists (Case Study of the tourism industry of Tajikistan), Archive of Sciences ,Journal,Vol 65, No. 8;Aug 2012, pp. 371-380.

[13] WTO (2006). Year book of Tourism Statistics, Vol 3.

[14] Zare,I . OjaghiAghjehKandi,m . Beheshti,a.(2011). Role EPS to Future Earning Changes. European Journal of Economics, Finance and Administrative Sciences. Issue 43,44-49. 